\title{
Spathodea campanulata bud fluid reinforced mechanical, hydrophilicity and degradation studies of poly (vinyl alcohol) matrix
}

\author{
Naganagouda Goudar ${ }^{1} \cdot$ Vinayak N. Vanjeri $^{1} \cdot$ Saraswati P. Masti ${ }^{2} \cdot$ Ravindra B. Chougale $^{1}$
}

Received: 28 January 2020 / Accepted: 2 March 2020 / Published online: 6 March 2020

(c) Springer Nature Switzerland AG 2020

\begin{abstract}
The present study aims to scrutinize the influence of Spathodea campanulata (SC) bud fluid on various properties of PVA. The different volumes of SC bud fluid doped PVA films were prepared by the solvent evaporation technique and analyzed by various characterization techniques. The molecular interactions of PVA with SC bud fluid was confirmed by FTIR studies. Tensile properties such as tensile strength and Young's modulus increased from $48 \pm 4$ to $59 \pm 10$ and $2069 \pm 110$ to $2537 \pm 404 \mathrm{MPa}$ respectively compared to PVA. The DSC measurements of prepared films depicted an increased glass transition temperature than PVA. The thermal stability of composite films was not affected compared to the pristine PVA. The XRD results of all the films represented a semi-crystalline material with a characteristic peak at $2 \theta=20^{\circ}$. The morphology studies revealed the homogeneous surface due to the good dispersion of SC bud fluid. The water contact angle findings shown the composite films were hydrophilic. Composite film solubility in water increased after the incorporation of SC bud fluid. The water vapor transmission rate of composite films were assessed. The Soil Burial tests indicated the degradation rate of PVA increased in composite films due to increased hydrophilicity.
\end{abstract}

\section{Graphical abstract}

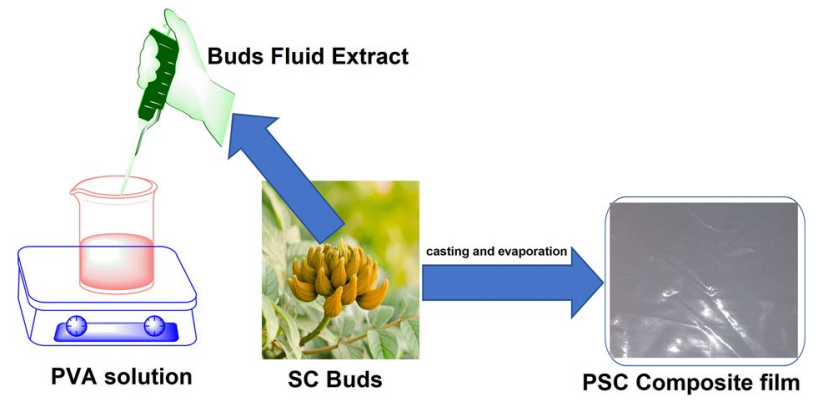

Keywords Spathodea campanulata $\cdot$ Poly (vinyl alcohol) $\cdot$ Composite films $\cdot$ Hydrophilicity

Ravindra B. Chougale, chougalerkud19@gmail.com | 1P G Department of Studies in Chemistry, Karnatak University, Dharwad 580 003, India. ${ }^{2}$ Department of Chemistry, Karnatak Science College, Dharwad 580 001, India. 


\section{Introduction}

The extreme usage of petroleum-based plastics which are non-biodegradable, severely damaged nature. About one-third of the total production of plastics is used in food packaging products. Researchers all over the world are trying to replace petroleum-based plastics by biodegradable plastics which are of less cost and efficient in terms of strength, flexibility, antioxidant, antimicrobial, chemical resistance and many more. To accomplish the requirements PVA was chosen as matrix because PVA is a synthetic, biodegradable, non-carcinogenic, water soluble and biocompatible polymer [1, 2]. PVA has excellent film forming ability, hydrophilicity and chemical stability. Therefore, it was blended with different synthetic and natural polymers [3-6]. It is used in various applications such as controlled drug delivery systems, recycling of polymers, film formation [7]. Although PVA is having reasonably good properties, efforts are being undertaken to improve some of the mechanical properties to make it comparable with other commodity plastics [8]. Natural extracts are the possible option to improve the biological activity and mechanical properties of the biodegradable polymers. To improve the properties of a biodegradable polymer there are various studies conducted using several natural extracts [9-14]. Spathodea campanulata $P$. Beauv (SC) is a flowering plant belonging to the Bignoniaceae family. In vitro antibacterial activity of leaf extracts of this plant against standard strains was evaluated [15]. Various phytochemical studies were performed with different parts of SC including stem barks, flowers, leaves and fruits. The stem barks contain Spathodic acid, steroids, saponins, ursolic acid, tomentosolic acid and pectic substances [16-19]. The molluscicidal activity was shown by flowers and stem bark extracts [20]. These are also used to treat diuretic and anti-inflammatory [21]. Banerjee $\&$ De showed the presence of anthocyanins in flowers of SC [22]. The stem bark preparations are used to treat fungal skin diseases, herpes, stomach aches and diarrhea [19], Hypoglycemic, anti-HIV and antimalarial activities were also observed in stem bark extracts $[23,24]$. The flower bud is brown, horn-shaped, and contains the fluid which circulates in the vascular system of a plant, consisting chiefly of water with dissolved sugars and mineral salts. It contains large pinnate foliage and large showy orange or scarlet, curved flattened, tulip-like flowers arranged in terminal panicles or racemes above the foliage at the top of the trees [25]. The SC bud fluid contains mainly alkanes, terpenoids, aromatic hydrocarbons, alcohols, carbonyl compounds, esters, lactones and phenols. There is only one survey in the literature regarding the isolation and identification of SC bud fluid components
\& around 35-60 compounds were isolated, identified by solvent extraction \& GC-MS respectively [25]. The major components which might be responsible for hydrogen bonding are given in Fig. 1.

The flower bud exudate was used to treat eyes related diseases $[25,26]$. These essential characteristics of Spathodea campanulata tree and bud fluid inspired us to select as a natural extract for our study. For the first time in the literature the SC bud fluid was doped into a polymer matrix and the consequences of SC bud fluid on multifunctional properties of PVA were studied exhaustively. There are no such reports available in the literature. The current study might be the basis for further exploration of SC bud fluid on different polymers in the coming days. The present investigation aims to optimize the SC bud fluid composition in the PVA matrix and to study the influence of SC bud fluid on the physicochemical properties of the PVA matrix.

\section{Experimental}

\subsection{Materials}

PVA (Molecular Weight 115,000, Degree of Hydrolysis 98-99 mol\%) was procured from Loba Chemicals, Mumbai. Millipore water used throughout the experiment. All the chemicals were used as received without any purification.

\subsection{Collection of Spathodea campanulata bud}

The SC buds were collected from its plant at Karnatak University Campus, Dharwad, Karnataka, India, and it was then authenticated by Botany Professor, Karnatak University, Dharwad. The collected buds were washed with double distilled water. The light brown color fluid was withdrawn from the bud with the help of a micro syringe and treated with charcoal at $35{ }^{\circ} \mathrm{C}$ to remove coloring impurity. The

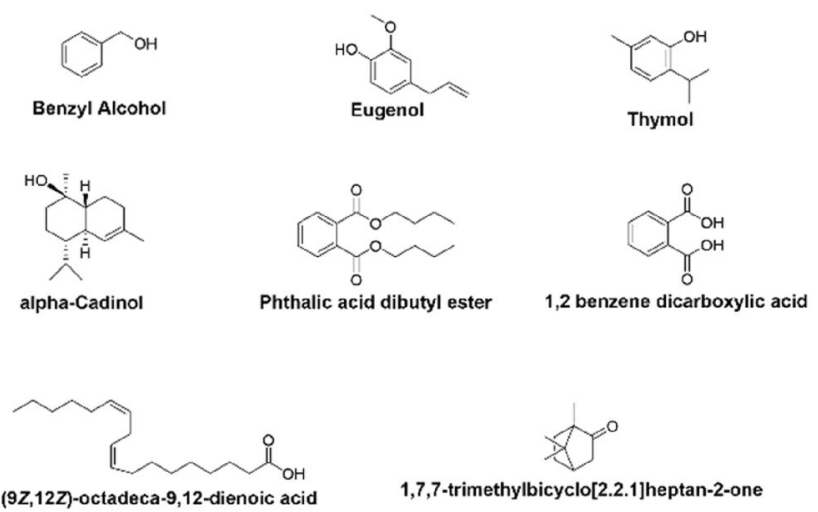

Fig. 1 The representative components of SC bud fluid 
filtered solution was kept in a vial covered with carbon paper until further use.

\subsection{Preparation of films}

The films were prepared by solution casting and solvent evaporation method. To prepare pure PVA film, an exactly weighed amount of PVA was dissolved in double distilled water with stirring at $80-90^{\circ} \mathrm{C}$ for an hour $(\mathrm{h})$ and allowed it to attain RT. The different volume of SC bud fluid was added to the PVA solution (coded as PSC) with the help of a microsyringe and stirred for $20 \mathrm{~h}$ at RT.

The homogeneous solution was then casted onto clean and dry Petri dishes for solvent evaporation at RT. After 6-7 days the films were peeled off from the Petri dishes and stored in desiccators until further use. The detailed composition is given in Table 1.

\section{Characterizations}

\subsection{Fourier Transform Infrared (FTIR) spectroscopy}

The interaction among the components was successfully examined with an attenuated total reflection (ATR) method of IR spectrometer [Fourier Transform Infrared (FTIR) spectroscopy-attenuated total reflection, Perki$\mathrm{nElmer}$ Spectrum Version 10.5.4]. Measurements were conducted between 400 and $4000 \mathrm{~cm}^{-1}$ at $4 \mathrm{~cm}^{-1}$ resolution.

\subsection{Mechanical properties}

The thickness of the prepared films was measured using a digital micrometer (Mitutoyo Digital Micrometer, high accuracy S700 series, Japan). Several thickness measurements were taken at several locations of each film and mean value was reported. A Universal Testing Machine (UTM, DAK System Instrument, Mumbai), was used to determine the tensile properties such as tensile strength $\left(T_{s}\right)$, Young's modulus $\left(Y_{m}\right)$, and elongation at break $\left(E_{b}\right)$ according to ASTM D882-91. Rectangular film samples of $2.5 \mathrm{~cm} \times 10 \mathrm{~cm}$ was cut with a sharp knife from the prepared film samples and then placed in the extension grip

Table 1 Composition of PSC composite films

\begin{tabular}{llll}
\hline Sample code & PVA & SC bud fluid & Thickness $(\mathrm{mm})$ \\
\hline PVA & $2 \mathrm{~g}$ & - & $0.06 \pm 0.01$ \\
PSC-1 & $2 \mathrm{~g}$ & $0.2 \mathrm{~mL}$ & $0.06 \pm 0.01$ \\
PSC-2 & $2 \mathrm{~g}$ & $0.4 \mathrm{~mL}$ & $0.05 \pm 0.01$ \\
PSC-3 & $2 \mathrm{~g}$ & $0.6 \mathrm{~mL}$ & $0.06 \pm 0.01$ \\
\hline
\end{tabular}

of the testing machine. The film samples were stretched at a crosshead speed $1 \mathrm{~mm} / \mathrm{min}$ at RT in air.

\subsection{Differential scanning calorimetry (DSC)}

The glass transition $\left(T_{g}\right)$ and melting temperature $\left(T_{m}\right)$ of the prepared films were analysed using Differential Scanning Calorimetry (Instrument: DSC Q20 V24.10 Build 122 TA Instruments, Walters LLC New Castle, Delaware, USA). The film samples of weight $2-3 \mathrm{mg}$ were sealed in an aluminium crucible and heated from $25^{\circ} \mathrm{C}$ to $400^{\circ} \mathrm{C}$ at $10^{\circ} \mathrm{C} /$ min in an inert $\mathrm{N}_{2}$ gas $(50 \mathrm{~mL} / \mathrm{min})$.

\subsection{Thermogravimetric analysis (TGA)}

Thermogravimetric analysis (TGA) was carried out on an equipment SDT Q600 V20.9 TA instruments. The samples of $5-10 \mathrm{mg}$ was taken and heated up until $600^{\circ} \mathrm{C}$ at a heating rate of $10^{\circ} \mathrm{C} / \mathrm{min}$ under $\mathrm{N}_{2}$ atmosphere $(100 \mathrm{~mL} / \mathrm{min})$.

\subsection{X-ray diffraction (XRD) study}

The change in structural properties of PVA was investigated using Rigaku D/Max-IIA, X-ray diffraction (XRD) (Tokyo, Japan). The radiation was generated from $\mathrm{Cu}-\mathrm{K}_{\beta}$ $(\lambda=1.5406 \AA)$ source at a voltage $40 \mathrm{kV}$ and $40 \mathrm{~mA}$ was used to scan the samples between $2 \theta=5^{\circ}-80^{\circ}$ with a scanning speed of $5 \% \mathrm{~min}$. The percentage of crystallinity was calculated by using the Eq. (1).

Crystallinity $(\%)=\frac{\text { Total Area of Crystalline Peaks }}{\text { Total Area of all Peaks }} \times 100$

\subsection{Scanning electron microscopy (SEM)}

The morphology of the prepared films was examined using a JEOL JSM-6360 Scanning Electron Microscopy (SEM) at an acceleration voltage of $10 \mathrm{kV}$. All specimens were sputter-coated with a conductive layer of gold to avoid charging to the high electron beam. The film specimens were mounted on metal stubs using double-sided sticky carbon tape.

\subsection{Atomic force microscopy (AFM)}

Atomic Force Microscopy (AFM) (Nanosurf Easyscan 2, Switzerland), were used for investigating the surface topography and morphology of the composite films at ambient temperature. Topographic images were obtained by contact angle mode using aluminium coated cantilever and images were captured at different locations. 


\subsection{Water contact angle (WCA) measurement}

Contact angle measurements were carried out to acquire information on the hydrophilicity of the film surfaces. A contact angle analyzer, SEO Phoenix, was used to determine the contact angle of water. The measurements were conducted at RT and the size of the drop was $7 \mu \mathrm{L}$ with all measured probe liquids. At least five measurements at different locations per test point were performed. Contact angle calculations were done with associated software. The results are presented as average \pm standard deviation.

\subsection{Water solubility (WS)}

To check out the stability of the prepared films in water, the solubility of films in water was carried out according to Shojaee-Aliabadi et al. [27]. In brief, initially, the prepared films were dried in an oven at $105 \pm 2^{\circ} \mathrm{C}$ to remove the moisture adhered to the surface. The dried samples of size $2 \times 2 \mathrm{~cm}^{2}$ were weighed and immersed in a beaker containing $40 \mathrm{~mL}$ of water and kept vigorous stirring for $6 \mathrm{~h}$ at RT. After $6 \mathrm{~h}$ the films were removed from the beaker and blotted with tissue paper and dried in an oven to get the final weight. The percentage of WS was calculated using the Eq. (2)

$W S(\%)=\frac{W i-W f}{W i} \times 100$

where $\mathrm{Wi}$ is the initial weight of samples, $\mathrm{Wf}$ is the final weight of samples.

\subsection{Water vapor transmission rate (WVTR) test}

The Test was conducted using the method described by Muhammad Salman Sarwar et al., with some modifications [28]. The glass bottle of $17.5 \mathrm{~mm}$ diameter was taken as container and filled with $10 \mathrm{~mL}$ of distilled water. The films were wrapped on the mouth of container and tightened with the Teflon tape. The initial weight of glass bottles (W1) were weighed and placed in an oven at $40^{\circ} \mathrm{C}$ for $24 \mathrm{~h}$. After $24 \mathrm{~h}$ the glass bottles were taken out of the oven and weighed again to get the final weight (W2). The WVTR was calculated using the Eq. (3).

$W V T R=\frac{W 1-W 2}{A} \times T \mathrm{~g} / \mathrm{m}^{2} \mathrm{~h}$

where $A$ is the area of the circular mouth of the glass bottle and $\mathrm{T}$ is the time $(24 \mathrm{~h})$.

\subsection{Soil burial test}

The biodegradability of the prepared films was studied by soil burial test under laboratory conditions according to the method described by Sa-Ad Riyajan et al. [29]. The fresh soil was collected from the Botanical garden, Karnatak University Campus, Dharwad, Karnataka, India. The samples were cut into $2 \times 2 \mathrm{~cm}^{2}$ and dried at $40{ }^{\circ} \mathrm{C}$ to get the initial dry weight (w1). The samples were buried in the soil at depth of about $8-10 \mathrm{~cm}$ under the soil surface. The moisture of soil was maintained by spraying water on the surface of the soil. The change in weight was recorded after 20 days by removing the films from soil and washing followed by drying in an oven (w2). The biodegradation was calculated using Eq. (4).

Biodegradation $(\%)=\frac{w 1-w 2}{w 1} \times 100$

\section{Results and discussion}

\subsection{Fourier transform infrared (FTIR) spectroscopy}

To affirm the interaction among the components in the given composition range FTIR was carried out. The FTIR spectra of PVA, PSC composites are shown in Fig. 2. The FTIR spectra of bare PVA showed a characteristic broad absorption peak at $3306 \mathrm{~cm}^{-1}$ attributed to the presence of $-\mathrm{OH}$ group. The weak absorption peaks at $2920 \mathrm{~cm}^{-1}$ and $2852 \mathrm{~cm}^{-1}$ are due to the asymmetric and symmetric stretching vibrations of $\mathrm{CH}_{2}$ group respectively $[30,31]$. The weak absorption peak observed at $1327 \mathrm{~cm}^{-1}$ is due to the $\mathrm{C}-\mathrm{OH}$ bending vibration. The peak at $1732 \mathrm{~cm}^{-1}$ is due to the presence of carbonyl $(\mathrm{C}=\mathrm{O})$ stretching of the

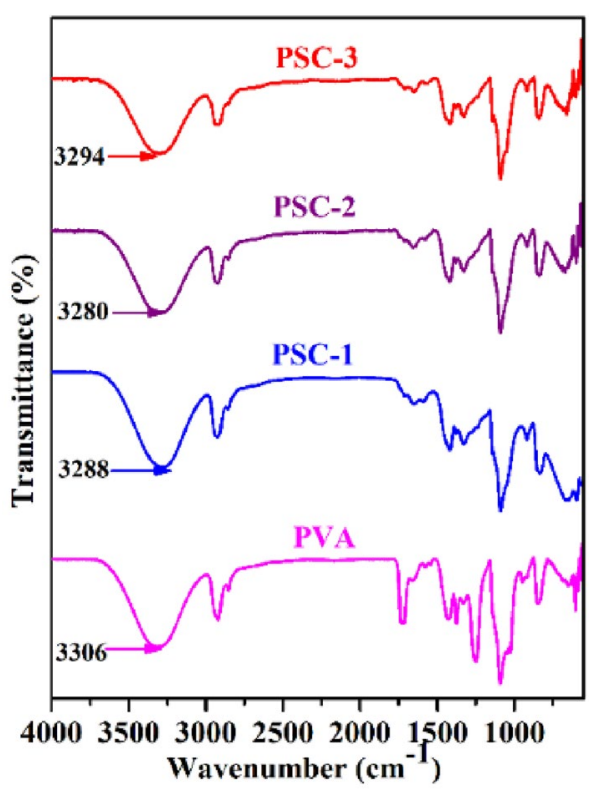

Fig. 2 FTIR spectra of neat PVA and PSC composite films 
non-hydrolysed residual vinyl acetate group of PVA [32]. The FTIR spectra of PSC composite films revealed different features. The interaction between the PVA and SC bud fluid was confirmed by observing the changes in the spectra of PSC composite films. In the FTIR spectra of PSC composite films, the broad peaks at 3288,3280 , and 3294 are assigned to $-\mathrm{OH}$ stretching of PVA.

The peak shifted from 3306 to $3280 \mathrm{~cm}^{-1}\left(26 \mathrm{~cm}^{-1}\right)$ indicates the considerable interaction of $-\mathrm{OH}$ groups of PVA with the polar groups of SC bud fluid components. The -OH group peak intensity of pure PVA was decreased successively after incorporating $\mathrm{SC}$ bud fluid indicates the intermolecular interaction between the two components. The intensity of peak at $1732 \mathrm{~cm}^{-1}(C=0)$ was decreased and also shifted to lower frequency after doping with SC bud fluid, this may be due to the hydrogen bonding of carbonyl group with the polar groups of SC bud fluid. The remaining IR spectral data are presented in Table 2.

\subsection{Tensile properties}

The mechanical properties such as tensile strength $\left(T_{s}\right)$, Young's modulus $\left(\mathrm{Y}_{\mathrm{m}}\right)$ and Elongation at break $\left(\mathrm{E}_{\mathrm{b}}\right)$ were assessed to know the strength and flexibility of the prepared films. The stress-strain curves are presented in Fig. 3. The PSC composite results are tabulated in Table 3. At lower volume of SC bud fluid, $T_{s}$ of the pure PVA was increased from $47.9 \pm 4$ to $59 \pm 10 \mathrm{MPa}$ and $Y_{m}$ was increased from $2069 \pm 110$ to $2537 \pm 404 \mathrm{MPa}$. But there was a decrease in $\mathrm{E}_{\mathrm{b}}$ which was decreased from $118.1 \pm 5 \%$ to $43.9 \pm 4.2 \%$, indicates the decrease in composite films flexibility, which is due to the restriction of the ductile flow of the polymer chains [33]. I. Korbag \& S. Mohamed Saleh, who studied the influence of lignin on mechanical and biodegradability of PVA also reported the same observation and mentioned that the addition of lignin into PVA matrix slightly decreases $E_{b}$ [34]. At lower content of SC bud fluid $(0.2 \mathrm{~mL})$, there was an increase in $\mathrm{T}_{\mathrm{s}}$ and $\mathrm{Y}_{\mathrm{m}}$, which corresponds to the uniform distribution of SC bud fluid in the PVA matrix [35]. As the content of SC bud fluid increased from $(0.4 \mathrm{~mL}$ to $0.6 \mathrm{~mL})$, the $T_{\mathrm{s}}$ and $Y_{\mathrm{m}}$ were decreased. Which may be due to the weak molecular interaction between the polar groups of $\mathrm{SC}$ bud fluid and $-\mathrm{OH}$ group

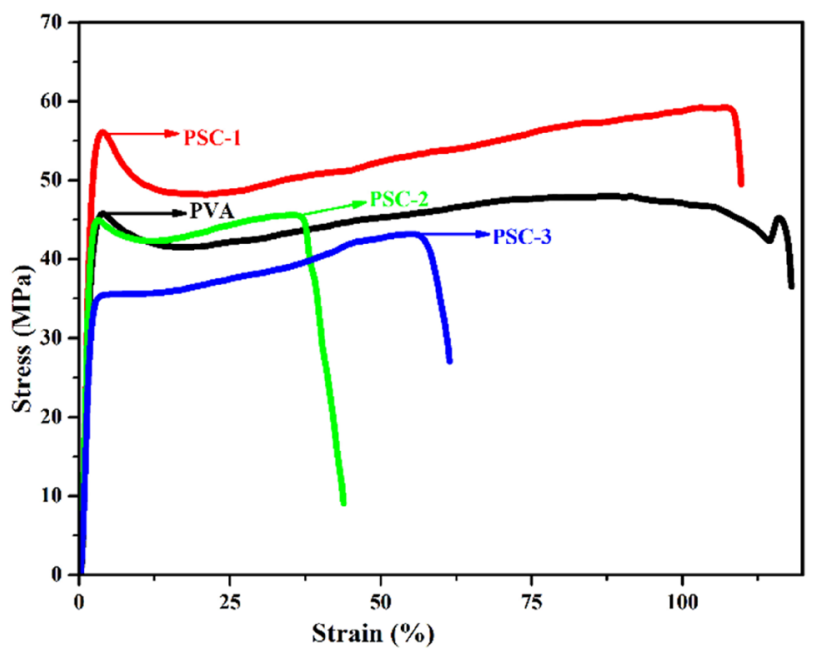

Fig. 3 stress-strain curves of blank PVA and PSC composite films

of PVA. The decrease in $T_{s^{\prime}} Y_{m}$, and $E_{b}$ at higher loading of SC bud fluid attributed to the insufficient interaction and bad compatibility or non-homogeneous dispersion induced by the SC bud fluid [17, 36, 37]. A negative correlation existed between properties $\mathrm{T}_{\mathrm{s}}, \mathrm{Y}_{\mathrm{m}}, \mathrm{E}_{\mathrm{b}}$ and content of $S C$ bud fluid, that is an increase in the volume of $S C$ bud fluid in the PVA matrix led to decreased $T_{s^{\prime}} Y_{m^{\prime}}$ and $E_{b}$. The present findings of this study are in good agreement with the literature reported by other researchers $[36,38]$. The results are relatable with the FTIR study.

\subsection{Differential scanning calorimetry (DSC)}

The crystallization and melting behavior of polymer composites strongly influences the macroscopic properties of materials [33]. To examine these parameters and also to find out the miscibility between the components, Differential Scanning Calorimetry (DSC) technique was used. The thermograms of neat PVA, PSC composite are shown in Fig. 4 and the data are given in Table 4. The Appearance of a small endothermic peak in all composite films below $80^{\circ} \mathrm{C}$ is due to loss of moisture [37, 39]. The neat PVA shows two endothermic peaks at $52.4^{\circ} \mathrm{C}$ and $189^{\circ} \mathrm{C}$ which corresponds to the glass transition
Table 2 FTIR Spectral data of neat PVA and PSC composite films

\begin{tabular}{llllll}
\hline Sample Code & $\begin{array}{l}-\mathrm{OH} \text { stretch- } \\
\text { ing }\left(\mathrm{cm}^{-1}\right)\end{array}$ & $\begin{array}{l}-\mathrm{CH}_{2} \text {-asymmetric } \\
\text { stretching }\left(\mathrm{cm}^{-1}\right)\end{array}$ & $\begin{array}{l}-\mathrm{CH}_{2} \text {-symmetric } \\
\text { stretching }\left(\mathrm{cm}^{-1}\right)\end{array}$ & $\begin{array}{l}-\mathrm{C}-\mathrm{OH} \text { bend- } \\
\text { ing }\left(\mathrm{cm}^{-1}\right)\end{array}$ & $\begin{array}{l}-\mathrm{C}-\mathrm{O}- \\
\text { stretching } \\
\left(\mathrm{cm}^{-1}\right)\end{array}$ \\
\hline PVA & 3306 & 2928 & 2852 & 1327 & 1090 \\
PSC-1 & 3288 & 2928 & 2853 & 1329 & 1089 \\
PSC-2 & 3280 & 2928 & 2852 & 1326 & 1088 \\
PSC-3 & 3294 & 2928 & 2851 & 1328 & 1087 \\
\hline
\end{tabular}


Table 3 Mechanical properties of PVA and PSC composite films

\begin{tabular}{llll}
\hline Sample code & Tensile strength $(\mathrm{MPa})$ & Young's modulus $(\mathrm{MPa})$ & Elongation at break (\%) \\
\hline PVA & $47.9 \pm 4.0$ & $2069.5 \pm 110$ & $118.1 \pm 5$ \\
PSC- 1 & $59.0 \pm 10.0$ & $2537.5 \pm 404$ & $109.7 \pm 20.1$ \\
PSC-2 & $45.0 \pm 5.4$ & $2210.4 \pm 346.3$ & $43.9 \pm 4.2$ \\
PSC-3 & $43.0 \pm 2.4$ & $1661.7 \pm 14.4$ & $61.4 \pm 8.1$ \\
\hline
\end{tabular}

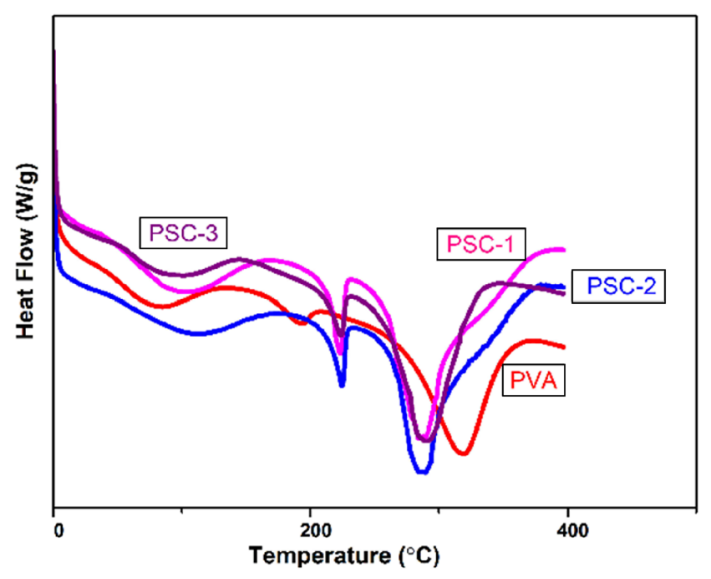

Fig. 4 DSC thermograms of PVA and PSC composite films

Table $4 T_{g}, T_{m}$ and $T_{d}$ of PVA and PSC composite films

\begin{tabular}{llll}
\hline Sample code & $\begin{array}{l}\text { Glass transition } \\
\text { temperature }\left(\mathrm{T}_{\mathrm{g}}\right) \\
\left({ }^{\circ} \mathrm{C}\right)\end{array}$ & $\begin{array}{l}\text { Melting tem- } \\
\text { perature }\left(\mathrm{T}_{\mathrm{m}}\right) \\
\left({ }^{\circ} \mathrm{C}\right)\end{array}$ & $\begin{array}{l}\text { Decomposition } \\
\text { temperature }\left(\mathrm{T}_{\mathrm{d}}\right) \\
\left({ }^{\circ} \mathrm{C}\right)\end{array}$ \\
\hline PVA & 52.4 & 192.7 & 319.0 \\
PSC-1 & 71.5 & 222.0 & 286.0 \\
PSC-2 & 78.5 & 224.0 & 287.0 \\
PSC-3 & 68.5 & 223.0 & 290.0 \\
\hline
\end{tabular}

temperature $\left(T_{g}\right)$, and melting temperature $\left(T_{m}\right)$ respectively [40]. After incorporating with SC bud fluid, the $T_{g}$ and $\mathrm{T}_{\mathrm{m}}$ increased from $52.4{ }^{\circ} \mathrm{C}$ to $78.5^{\circ} \mathrm{C}$ and $189^{\circ} \mathrm{C}$ to $222^{\circ} \mathrm{C}$ respectively, indicating the strong intermolecular interaction between the matrix and bud fluid components. In the present study increase in the $T_{g}$ value for PSC composite films may be attributed to the hydrogen bonds formed between polyphenolic compounds such as benzyl alcohol, trans-verbenol, Eugenol, linoleic acid [41] of bud fluid and -OH groups of PVA. Similar results were reported by other authors working on different plant extracts [57]. A single endothermic peak between the temperature range of $50-120^{\circ} \mathrm{C}$ viz a single $T_{g}$ for all the films proves the miscibility of matrix and bud fluid over the given composition [35].
Table 5 Thermal properties of pure PVA and PSC composite films

\begin{tabular}{llll}
\hline Sample code & $\begin{array}{l}\text { Weight loss (\%) } \\
\text { I }\end{array}$ & $\begin{array}{l}\text { Weight loss (\%) } \\
\text { II }\end{array}$ & $\begin{array}{l}\text { Weight loss (\%) } \\
\text { III }\end{array}$ \\
\hline PVA & $20.11 \%$ & $69.92 \%$ & $14.07 \%$ \\
& $\left(39.6-93.9^{\circ} \mathrm{C}\right)$ & $\left(248.6-299.8^{\circ} \mathrm{C}\right)$ & $\left(407-461.7{ }^{\circ} \mathrm{C}\right)$ \\
PSC-1 & $20.99 \%$ & $62.75 \%$ & $15.34 \%$ \\
& $\left(42.2-85.9{ }^{\circ} \mathrm{C}\right)$ & $\left(243-296.3^{\circ} \mathrm{C}\right)$ & $\left(404-460{ }^{\circ} \mathrm{C}\right)$ \\
PSC-2 & $16.33 \%$ & $72.82 \%$ & $14.77 \%$ \\
& $\left(43.4-108.4^{\circ} \mathrm{C}\right)$ & $\left(249-294^{\circ} \mathrm{C}\right)$ & $\left(405.6-462.3^{\circ} \mathrm{C}\right)$ \\
PSC-3 & $15.55 \%$ & $59.77 \%$ & $11.45 \%$ \\
& $\left(56.5-107{ }^{\circ} \mathrm{C}\right)$ & $\left(251.8-293.4^{\circ} \mathrm{C}\right)$ & $\left(404.8-462.5^{\circ} \mathrm{C}\right)$ \\
\hline
\end{tabular}

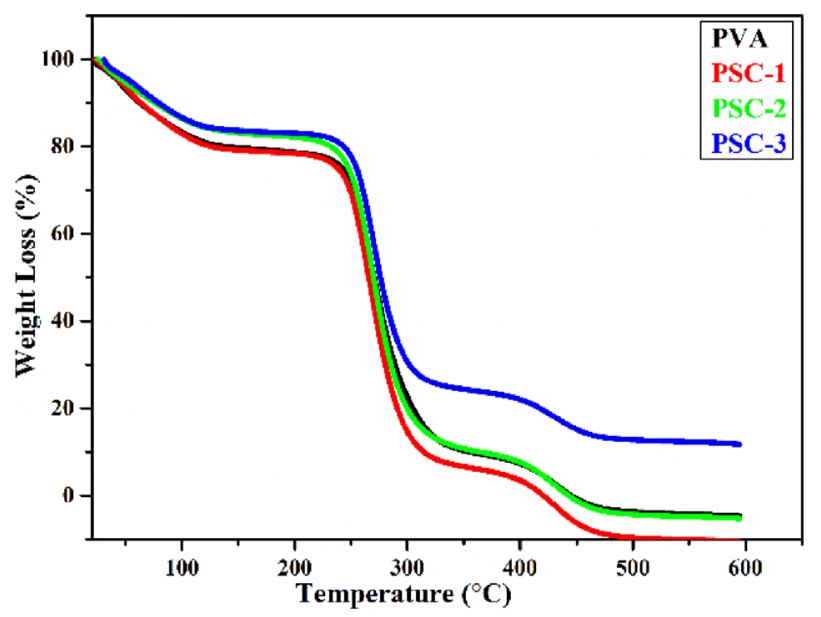

Fig. 5 TGA thermograms of PVA and PSC composite films

\subsection{Thermogravimetric Analysis (TGA)}

To study the influence of SC bud fluid on the thermal stability of PVA the TGA was carried out. The TGA thermograms of pristine PVA and PSC composite films are shown in Fig. 5. All the films including pure PVA have shown three stage degradation patterns. The neat PVA shows first degradation step at $39.6-93.9^{\circ} \mathrm{C}(20.11 \%)$ which is due to the elimination of physisorbed water molecules [42]. The second major weight loss of PVA has occurred at $248-299^{\circ} \mathrm{C}$ $(69 \%)$ is ascribed to the elimination of acetate groups of PVA via chain scission reaction. The third weight loss occurred at $407-461{ }^{\circ} \mathrm{C}$ is attributed to decomposition of residual groups of PVA [43]. After incorporation of SC bud 
fluid into the PVA matrix, the thermal stability of composite films was decreased by $4-5^{\circ} \mathrm{C}$ as shown in Table 5 . The neat PVA has exhibited a residue of $14.07 \%$ which is due to carbonaceous residue. The PSC -1 and PSC- 2 has residue of $15.34 \%$ and $14.77 \%$ respectively, due to a minor increase in the resistance to thermal degradation process. But the PSC-3 has residue of $11.45 \%$ which is much lesser than PVA, PSC-1 and PSC-2 indicating the lesser thermal stability of PSC-3 compared to PSC- 1 and PSC-2. As for as PSC-3 residue is concerned, the residue is mainly due to the carbonaceous residue of PVA and not due to the SC bud fluid. The components of SC bud fluid degrade in the first and second degradation step only. The decreased thermal stability of the composite films might be due to the lesser stability of SC bud fluid to the temperature. The similar results were reported by Kasai et al., who studied the influence of Piper nigrum leaves extract on physicochemical properties of $\mathrm{CH} / \mathrm{PVA}$ blend films [35]. The decreased thermal stability of the composite films is contrary to the FTIR, DSC and mechanical properties results.

The increased intermolecular interaction might accelerate the water molecule evaporation from the composite films ultimately reducing the thermal stability [44]. The detailed data of the thermal degradation process of composite films are presented in Table 5 .

\subsection{X-ray diffraction (XRD) study}

Figure 6. shows the X-ray diffractograms of the blank PVA and PSC composite films. The characteristic diffraction peaks of neat PVA occurred at $2 \theta=19.6^{\circ}$ and $40.7^{\circ}$ which is attributed to the semicrystalline nature of PVA $[9,45-47]$. The small hump at $40^{\circ}$ was also characteristic for PVA [48]. The percentage of crystallinity of PVA was found to be 29. After incorporating the SC bud fluid into PVA matrix, there are no much changes in the diffraction peaks of PVA but there is an increase in the percentage of crystallinity from 36.6 to $54.5 \%$, indicating the considerable interaction between the -OH groups of PVA and the active groups of SC fluid. The intensity of the broad peak at $2 \theta=19.6$ was decreased after blending it with SC bud fluid. It was observed that the addition of SC bud fluid does not affect the crystal type of the film, which means that the SC bud fluid has been uniformly distributed inside the host polymer [49]. The diffractograms of PSC composite films represented a typical property of partially crystalline materials with a characteristic peak at $2 \theta=20^{\circ}$ and are similar to the results reported by other authors $[50,51]$. The percentage of crystallinity calculated from diffracted intensity data of PSC composite films are presented in Table 6. The percentage of crystallinity of all PSC composite films was increased compared to bare PVA film leading
Table 6 Percentage of crystallinity of PVA and PSC composite films

\begin{tabular}{lll}
\hline Sample code & 2 Theta (degree) & Crystallinity (\%) \\
\hline PVA & 19.6 & $25 \pm 4$ \\
PSC-1 & 19.6 & $29 \pm 9$ \\
PSC-2 & 19.6 & $28 \pm 6$ \\
PSC-3 & 19.6 & $31 \pm 4$ \\
\hline
\end{tabular}

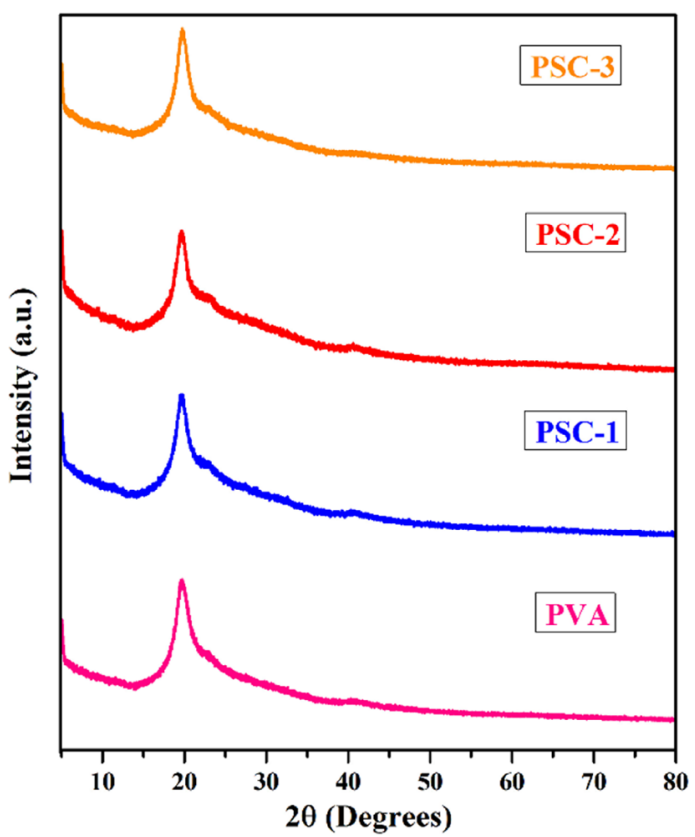

Fig. 6 X-ray diffraction pattern of neat PVA and PSC composite films

to less flexible and more strengthened films as witnessed by mechanical properties.

\subsection{Scanning electron microscopy (SEM)}

The consequence of SC bud fluid on microstructure of PVA was analysed with SEM. The SEM micrographs of neat PVA and PSC composite films are shown in Fig. 7. The control film (PVA) exhibits smooth and homogeneous compact microstructure without any visible depressions. With the addition of SC bud fluid into the PVA matrix, the change in morphology of composite films was observed based on the composition of bud fluid. At lower content of SC bud fluid, the films were homogeneous with some visible agglomeration of bud fluid components. The patches were observed after the addition of SC bud fluid into the PVA matrix which might be due to the nonhomogeneous distribution of bud fluid over the surface. The PSC- 1 and PSC-2 composite films exhibited such type of morphology, in PSC-2 it was more clearly visible. The possible reason for 

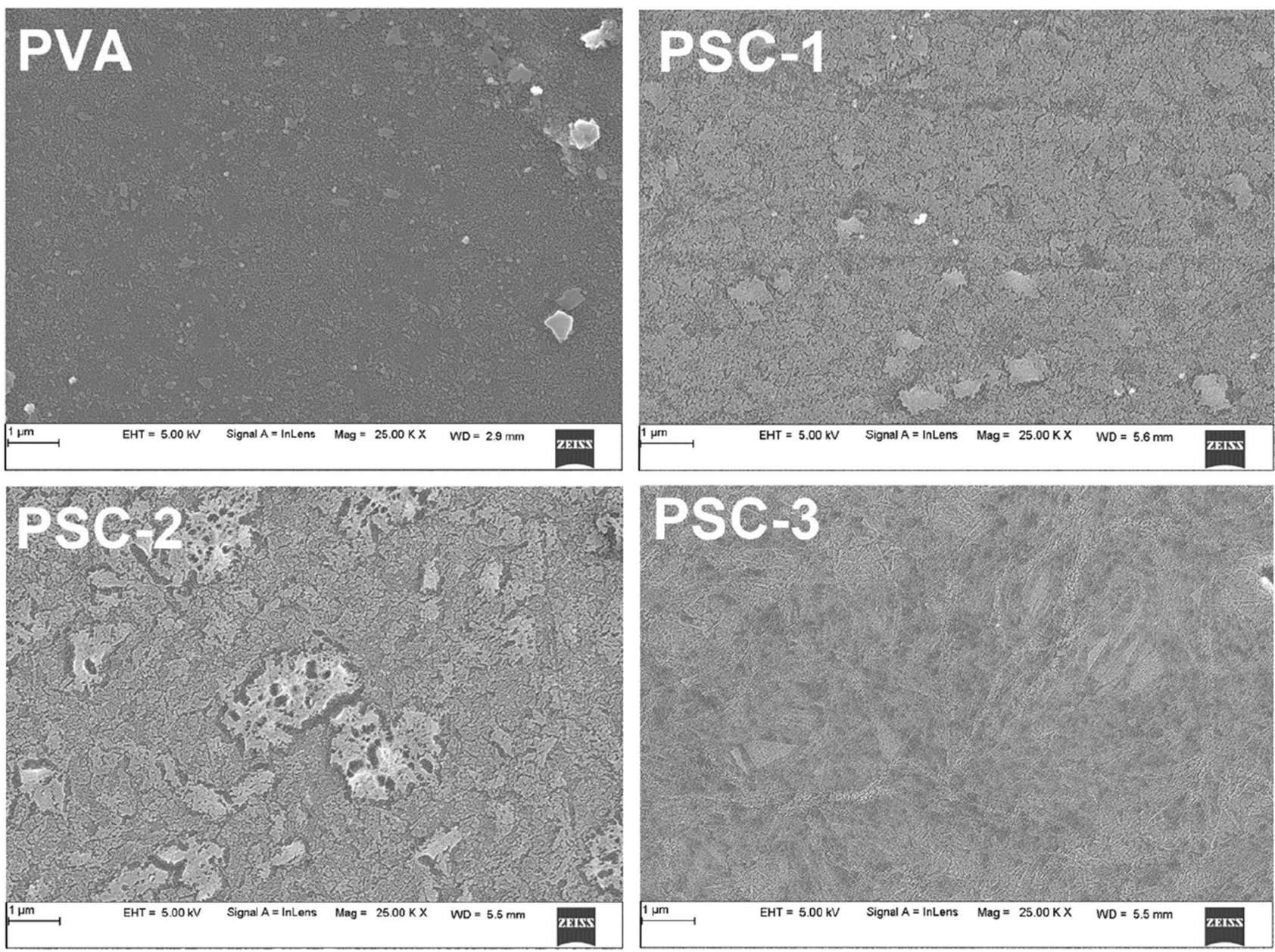

Fig. 7 SEM micrographs prepared composite films.(Magnification: 25.00 K)

this observation is that the PVA contains numerous - $\mathrm{OH}$ groups and SC bud fluid also contains the -OH groups that has resulted in the crosslinked network. Another reason for the current observation might be due to the coalescence phenomenon during the solvent evaporation process. At higher content of SC bud fluid, the surface was uneven, coarse and fluctuant due to lack of compatibility between the PVA matrix and bud fluid components. The lesser compatibility between the PVA matrix and bud fluid components could be due to the agglomeration of bud fluid components at a higher content. The current scenario is well cited in the literature [35, 36, 52-54].

\subsection{Atomic force microscopy (AFM)}

Atomic Force Microscopy was carried out to obtain the qualitative and quantitative surface parameters of the prepared films. The AFM images and respective 3D images of neat PVA and different composite films are shown in Fig. 8. The Parameters such as line roughness $(\mathrm{Rq})$ and area roughness $(\mathrm{Sq})$ are obtained with the associated software and summarized in Table 7. The surface morphology of neat PVA film is smooth and homogeneous. The surface morphology of PSC composite films varied after incorporation of bud fluid. At lower content of SC bud fluid, the composite films are less rough than higher content loaded composite films. Indicating the good homogeneity and compatibility at lower content $(0.2 \mathrm{~mL})$ of SC bud fluid. As the volume of SC bud fluid increased, (from $0.2 \mathrm{~mL}$ to $0.6 \mathrm{~mL}$ ) the line roughness $(\mathrm{Rq})$ increased from $10.5 \mathrm{~nm}$ to $21.1 \mathrm{~nm}$ and also area roughness (Sq) increased from $9.3 \mathrm{~nm}$ to $20.1 \mathrm{~nm}$. This indicates that at higher volume of bud fluid, the composite films are rougher. The PSC-3 composite film exhibited more heterogeneity. The present observation is in good agreement with the previous research works $[27,52,55]$.

\section{SN Applied Sciences}



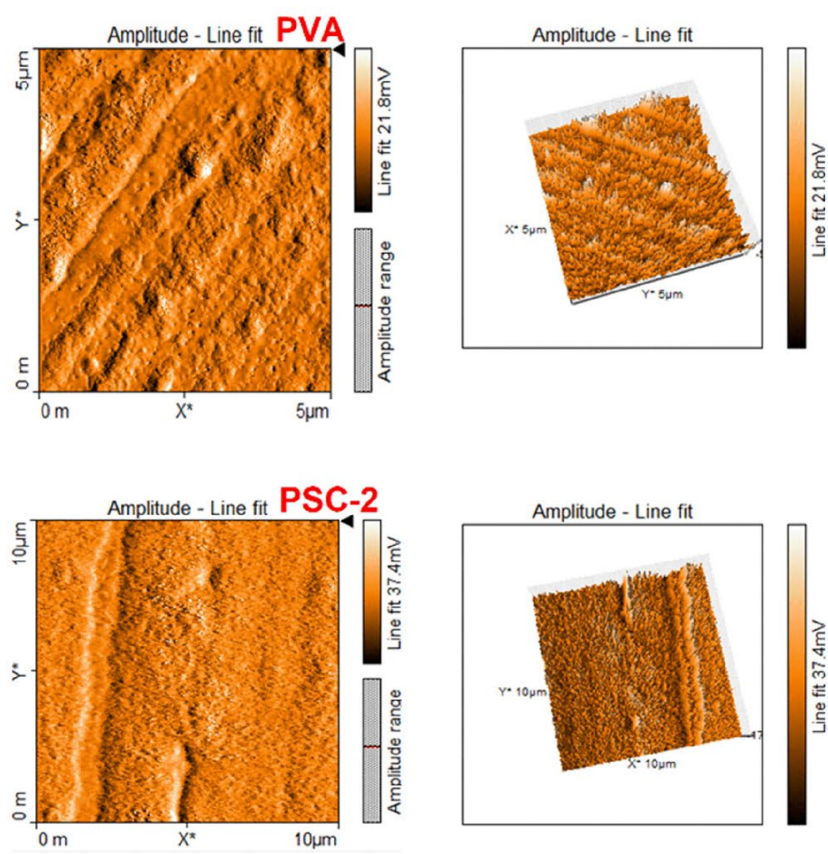

Fig. 8 AFM micrographs of neat PVA and prepared composite films

Table 7 Line roughness $(\mathrm{Rq})$ and area roughness $(\mathrm{Sq})$ of neat PVA and PSC composite films

\begin{tabular}{llc}
\hline Sample code & $\begin{array}{l}\text { Line roughness }(\mathrm{Rq}) \\
(\mathrm{nm})\end{array}$ & $\begin{array}{l}\text { Area rough- } \\
\text { ness }(\mathrm{Sq}) \\
(\mathrm{nm})\end{array}$ \\
\hline PVA & $9.00 \pm 1.1$ & $10.2 \pm 1.2$ \\
PSC-1 & $10.5 \pm 1.2$ & $9.3 \pm 0.8$ \\
PSC-2 & $16.6 \pm 1.0$ & $20.1 \pm 1.3$ \\
PSC-3 & $21.1 \pm 0.6$ & $16.1 \pm 5.2$ \\
\hline
\end{tabular}

\subsection{Water contact angle (WCA) measurement}

To understand the surface wettability, all the films were analyzed with water contact angle analyzer using sessile drop method. The surface hydrophobicity is crucial, as it determines the water resistance of a packaging material, which helps to maintain the quality of food products [55]. This contact angle is a measure of the non-covalent forces between the ultrapure water and the first monolayer (surface) of the films and is an indicator of their superficial hydrophilic/hydrophobic properties [56]. The contact angle of the neat PVA and PSC composite films were presented Fig. 9. The contact angle of pristine PVA film was found to be $55^{\circ}$ indicating the hydrophilic nature of PVA. The PSC composite films show drastic changes in the contact angle. At lower volume of SC bud fluid, there is an increase in the hydrophilicity, which is attributed to
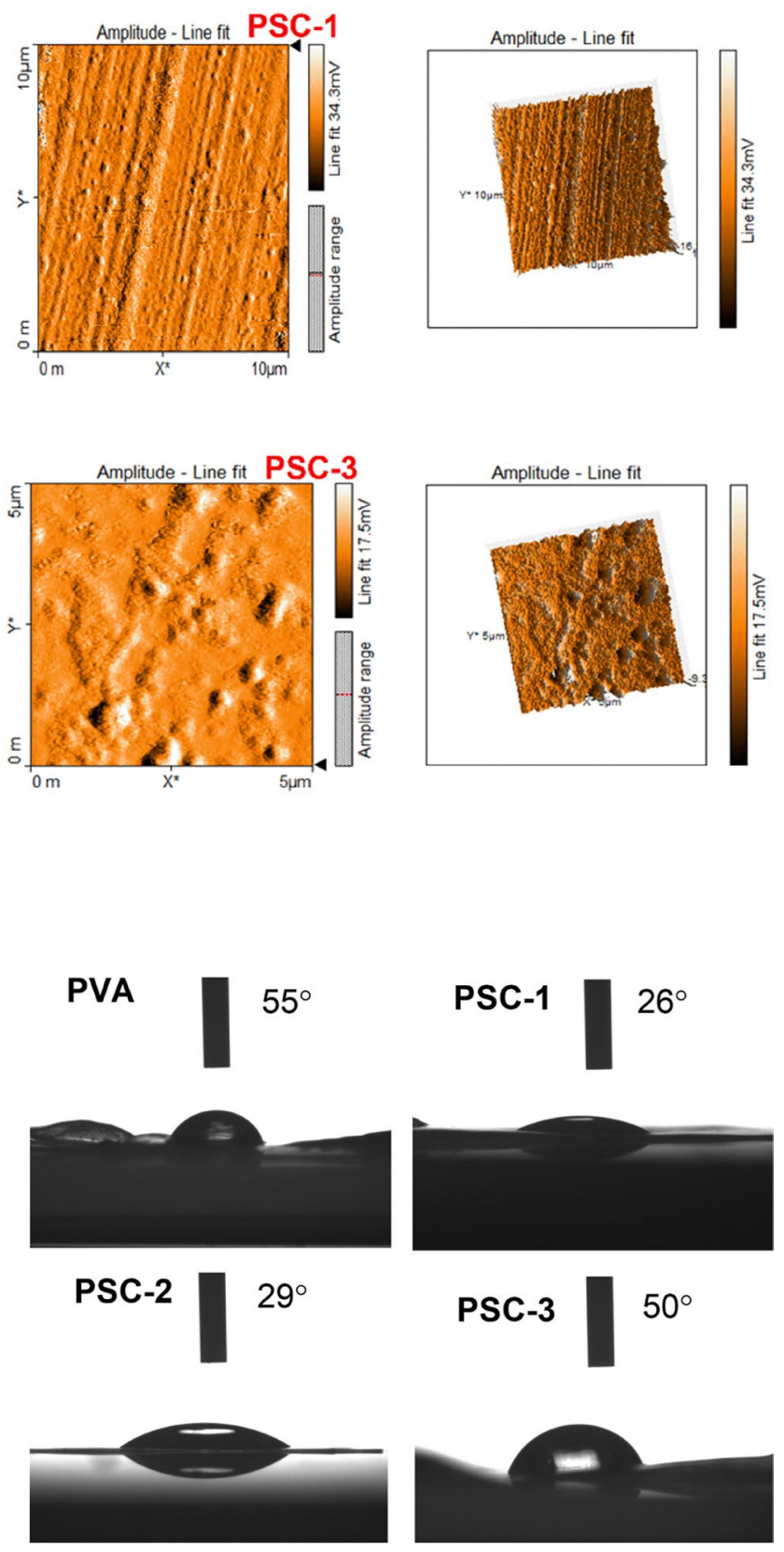

Fig. 9 Water contact angle images of neat PVA and PSC composite films

the strong intermolecular hydrogen bonding between the $-\mathrm{OH}$ groups of PVA and the polar groups of SC bud fluid. At this content of SC bud fluid, the composite films were more hydrophilic than the neat PVA film.The present findings are in good agreement with the FTIR and mechanical properties of composite films. The increased wettability of the composite films may be due to the hydrophilicity of added SC bud fluid [57]. 


\subsection{Water solubility (WS)}

Water Solubility is a crucial property in food packaging applications because potential applications could require partial water solubility to enhance food integrity and water resistance $[58,59]$. The results of solubility test of PVA and composite films are presented in Fig. 10. The neat PVA has shown $32 \%$ of water solubility and PSC composite films shows an increased solubility compared to pure PVA which is in good agreement with WCA results. The high solubility of composite films is due to the increased hydrogen bonding and presence of highly polar components of SC bud fluid.

\subsection{Water vapor transmission rate (WVTR)}

The WVTR is a key feature for a food packaging material and it must be low. WVTR was studied to check out the potentiality of prepared films for food packaging applications. The influence of SC bud fluid on WVTR of PVA matrix was studied. The obtained results are presented in Fig. 10. The neat PVA has shown WVTR of $39 \mathrm{~g} / \mathrm{m}^{2}$.day. After the incorporation of SC bud fluid into the matrix, the WVTR increased to a maximum of $43 \mathrm{~g} / \mathrm{m}^{2}$.day which might be due to the high hydrophilicity of composite films. The WVTR findings of composite films are relatable to WCA and WS results.

\subsection{Soil burial test}

The influence of SC bud fluid on the soil degradation rate of PVA was studied in laboratory conditions. The neat PVA requires around 90 days for $30.2 \%$ degradation [60]. The results of soil burial tests are presented in Fig. 11. After

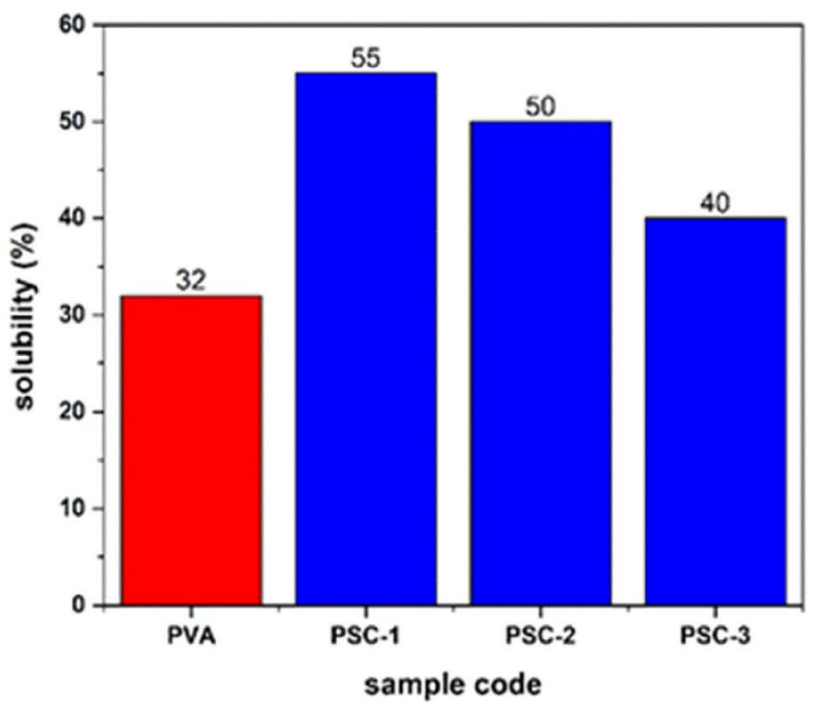

Fig. 10 Solubility and WVTR of PVA and PSC composite films

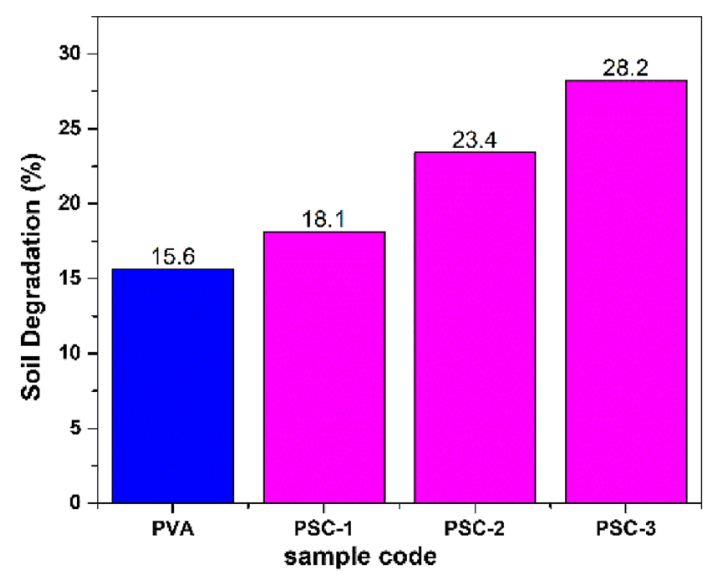

Fig. 11 Soil Degradation rate of PVA and PSC composite films

20 days the PSC composite film's appearance become shrank by the action of microorganisms, indicating the degradation. The neat PVA has presented $15.6 \%$ degradation in the soil after 20 days of burial. The incorporation of SC bud fluid into the PVA matrix accelerated the soil degradation process, which might be due to the highly hydrophilic nature and early degradation of small molecules of plant extract. The composite film's weight loss varied from 18 to $28 \%$. The Soil degradation rate of PVA was greatly enhanced by the incorporation of SC bud fluid.

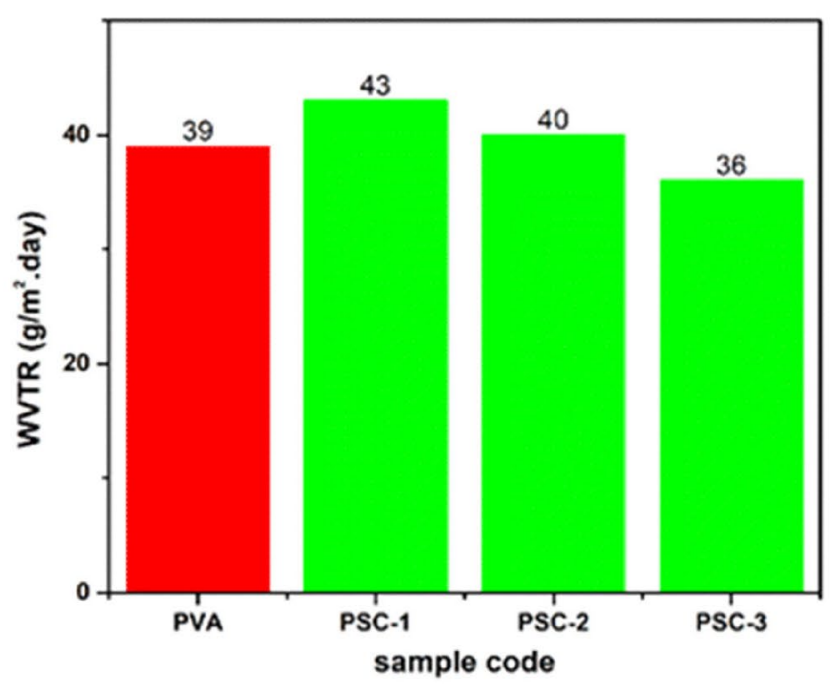




\section{Conclusion}

In this present contribution, SC bud fluid incorporated PVA composite films were successfully prepared by the solvent evaporation technique and characterized. The interaction among the components was corroborated by FTIR studies. The $T_{s}$ and $Y_{m}$ of PSC composite films were greatly improved. The incorporation of SC bud fluid into the matrix has increased the $T_{g}$ at a lower volume. The thermal stability of PSC composite films was not affected by the incorporation of SC bud fluid. The composite films exhibited semicrystalline property. The morphology studies revealed homogeneity at a lower amount of SC bud fluid. The prepared PSC composite films were hydrophilic. The WS results suggested the high solubility of composite films in water. The WVTR of PSC composite films were increased due to the hydrophilicity of the films, the soil degradation rate of PVA was improved in composite films. Based on the above results, the optimal content of SC bud fluid to dope into the PVA matrix is $0.2 \mathrm{~mL}$. There is a chance for further exploration of the current study to reach the desired application level.

Acknowledgements One of the authors Mr. Naganagouda Goudar would like to thank the Council of Scientific and Industrial Research (CSIR) New Delhi, India, for awarding the Junior Research Fellowship (JRF). Authors thank the University Science Instrumentation Centre (USIC), DST-SAIF and DST PURSE-Phase II programme, Karnatak University, Dharwad, Karnatak, for providing the instrumentation facility. Authors would like to thank Department of Chemistry, Karnatak Science College, Dharwad - 580001, for providing the Universal Testing Machine (UTM) facility to study the tensile properties of PVA based films.

\section{Compliance with ethical standards}

Conflict of interest On behalf of all authors, the corresponding author states that there is no conflict of interest.

\section{References}

1. Kim D, Jung J, Park S, Seo J (2015) Preparation and characterization of LDPE/PVA blend films filled with glycerin-plasticized polyvinyl alcohol. J Appl Polym Sci 41985:1-8

2. Ahmed A, Niazi MBK, Jahan Z et al (2019) Enhancing the thermal, mechanical and swelling properties of PVA/starch nanocomposite membranes incorporating g-C3N4. J Polym Environ 28(1):100-115

3. Yan J, Tian H, Zhang Y, Xiang A (2015) Effect of urea and formamide plasticizers on starch/PVA bioblend sheets. J Appl Polym Sci 42311:1-8

4. Shawky HA (2009) Synthesis of ion-imprinting chitosan/PVA crosslinked membrane for selective removal of $\mathrm{Ag}(\mathrm{I})$. J Appl Polym Sci 114:2608-2615

5. Sonker AK, Rathore K, Teotia AK et al (2018) Rapid synthesis of high strength cellulose-poly ( vinyl alcohol) ( PVA ) biocompatible composite films via microwave crosslinking. J Appl Polym Sci 47393:27-30

6. Jung G, Kim H (2014) Synthesis and Photocatalytic Performance of PVA/TiO2/graphene-MWCNT nanocomposites for dye removal. J Appl Polym Sci 40715:1-7

7. Tripathi S, Mehrotra GK, Dutta PK (2010) Preparation and physicochemical evaluation of chitosan/poly(vinyl alcohol)/pectin ternary film for food-packaging applications. Carbohydr Polym 79:711-716

8. Kumar SV, George J, Sajeevkumar VA (2018) PVA based ternary nanocomposites with enhanced properties prepared by using a combination of rice starch nanocrystals and silver nanoparticles. J Polym Environ 26:3117-3127

9. Ahmadi R, Ghanbarzadeh B, Ayaseh A et al (2019) The antimicrobial bio-nanocomposite containing non-hydrolyzed cellulose nanofiber (CNF) and Miswak (Salvadora persica L.) extract. Carbohydr Polym 214:15-25

10. Akhtar MJ, Jacquot M, Jasniewski J et al (2012) Antioxidant capacity and light-aging study of HPMC films functionalized with natural plant extract. Carbohydr Polym 89:1150-1158

11. Estevez-areco S, Goyanes S (2019) Potato starch-based biocomposites with enhanced thermal, mechanical and barrier properties comprising water-resistant electrospun poly (vinyl alcohol) fibers and yerba mate extract. Carbohydr Polym 215:377-387

12. Chranioti C, Nikoloudaki A, Tzia C (2015) Saffron and beetroot extracts encapsulated in maltodextrin, gum Arabic, modified starch and chitosan: Incorporation in a chewing gum system. Carbohydr Polym 127:252-263

13. Medina C, Gutiérrez TJ, Goyanes S et al (2016) Biodegradability and plasticizing effect of yerba mate extract on cassava starch edible films. Carbohydr Polym 151:150-159

14. Medina-jaramillo C, Ochoa-yepes O, Bernal C, Famá L (2017) Active and smart biodegradable packaging based on starch and natural extracts. Carbohydr Polym 176:187-194

15. Kowti R, Gulzar Ahmed M, Gowda TS et al (2010) Antimicrobial activity of ethanol extract of leaf and flower of Spathodea campanulata P. Beauv. RJPBCS 1:691

16. Ilodigwe EE, Akah PA, Nworu CS (2010) Anticonvulsant activity of ethanol leaf extract of Spathodea campanulata P. Beauv (Bignoniaceae). J Med Food 13:827-833

17. Ngouela S, Nyasse B, Tsamo E et al (1990) Spathodic acid: a triterpene acid from the stem bark of Spathodea campanulata. Phytochemistry 29:3959-3961

18. Ngouela S, Tsamo E, Sondengam B (2007) Extractives from bignoniaceae: constituents of the stem bark of Spathodea campanulata. Planta Med 54:476-476

19. Silva C, Torres MD, Chenlo F, Moreira R (2017) Calyx-water consumption by blue-and-yellow macaws in Spathodea campanulata (Bignoniaceae) floral buds. Ornitologia Neotropical 26:201-206

20. Mendes NM, Souza CP, Araújo N, Pereira JP, Katz N (1986) Atividade moluscicida de alguns produtos naturais sobre Biomphalaria glabrate. Mem Inst Oswaldo Cruz Rio de Janeiro 81:87

21. Boniface PK, Verma S, Shukla A et al (2014) Membrane stabilisation: a possible anti-inflammatory mechanism for the extracts and compounds from Spathodea campanulata. Nat Prod Res 28:2203-2207

22. Banerjee $A, D e B$ (2001) Anthocyanins in some flowers of West Bengal. J Med Arom Plant Sci 23:600-604

23. Makinde J, Amusan O, Adesogan E (1987) The antimalarial activity of Spathodea campanulata Stem Bark Extract on Plasmodium berghei berghei in Mice. Planta Med 54:122-125

24. Niyonzima G, Laekeman G, Witvrouw M et al (1999) Hypoglycemic, anticomplement and anti-HIV activities of Spathodea campanulata stem bark. Phytomedicine 6:45-49 
25. Eid HH, Shehab NG, El Zalabani SM (2014) GC-MS profile and cytotoxicity of the hydrodistilled and extracted volatiles of the buds and flowers of Spathodea campanulata P. Beauv. J Biol Act Prod from Nat 4:196-208

26. Adio Gbemisola I, Faluyi JO, Osoniyi O (2014) Evaluation of the effect of Spathodea campanulata flower bud exudate on cataractogenesis in rat lenses. Afr J Tradit Complement Altern Med 11:83-91

27. Shojaee-Aliabadi S, Hosseini H, Mohammadifar MA et al (2013) Characterization of antioxidant-antimicrobial k-carrageenan films containing Satureja hortensis essential oil. Int J Biol Macromol 52:116-124

28. Sarwar MS, Bilal M, Niazi K et al (2018) Preparation and characterization of PVA/nanocellulose/Ag nanocomposite films for antimicrobial food packaging. Carbohydr Polym 184:453-464

29. Riyajan S-A (2019) Environmentally friendly novel maleated poly(vinyl alcohol)grafted 1, 4-butanediol modified with biopolymer for encapsulation of capsaicin. J Polym Environ 27:2637-2649

30. Choo K, Ching YC, Chuah CH et al (2016) Preparation and characterization of polyvinyl alcohol-chitosan composite films reinforced with cellulose nanofiber. Materials (Basel) 9:644

31. Guzman-Puyol S, Ceseracciu L, Heredia-Guerrero JA et al (2015) Effect of trifluoroacetic acid on the properties of polyvinyl alcohol and polyvinyl alcohol-cellulose composites. Chem Eng J 277:242-251

32. Lee SV, Halim NA, Arof AK, Abidin ZHZ (2013) Characterisation of poly(vinyl alcohol) coating mixed with anthocyanin dye extracted from roselle flower with different nitrate salt. Pigment Resin Technol 42:146-151

33. Díez-Pascual AM, Xu C, Luque R (2014) Development and characterization of novel poly(ether ether ketone)/ZnO bionanocomposites. J Mater Chem B 2:3065-3078

34. Korbag I, Mohamed Saleh S (2016) Studies on mechanical and biodegradability properties of PVA/lignin blend films. Int J Environ Stud 73:18-24

35. Kasai D, Chougale R, Masti S et al (2019) An investigation into the influence of filler Piper nigrum leaves extract on physicochemical and antimicrobial properties of chitosan/poly (vinyl alcohol) blend films. J Polym Environ 27:472-488

36. Kasai D, Chougale R, Masti S et al (2018) Influence of Syzygium cumini leaves extract on morphological, thermal, mechanical, and antimicrobial properties of PVA and PVA/chitosan blend films. J Appl Polym Sci 135:1-17

37. Li JH, Hong RY, Li MY et al (2009) Effects of ZnO nanoparticles on the mechanical and antibacterial properties of polyurethane coatings. Prog Org Coatings 64:504-509

38. El-Hefian EA, Nasef MM, Yahaya AH (2012) Mechanical, thermal and surface investigations of chitosan/agar/PVA ternary blended films. E J Chem 8:S105-S112

39. Ahmadizadegan $H$ (2016) Synthesis and gas transport properties of novel functional polyimide/ZnO nanocomposite thin film membranes. RSC Adv 6:106778-106789

40. Luzi F, Fortunati E, Di Michele A et al (2018) Nanostructured starch combined with hydroxytyrosol in poly(vinyl alcohol) based ternary films as active packaging system. Carbohydr Polym 193:239-248

41. Asad M, Saba N, Asiri AM et al (2018) Preparation and characterization of nanocomposite films from oil palm pulp nanocellulose/poly (Vinyl alcohol) by casting method. Carbohydr Polym 191:103-111

42. Wu Y, Ying Y, Liu Y et al (2018) Preparation of chitosan/poly vinyl alcohol films and their inhibition of biofilm formation against $P$ seudomonas aeruginosa PAO1. Int J Biol Macromol 118:2131-2137

43. Fortunati E, Puglia D, Luzi F et al (2013) Binary PVA bio-nanocomposites containing cellulose nanocrystals extracted from different natural sources: Part I. Carbohydr Polym 97:825-836
44. Zhang $\mathrm{X}$, Liu Y, Yong $\mathrm{H}$ et al (2019) Development of multifunctional food packaging films based on chitosan, $\mathrm{TiO}_{2}$ nanoparticles and anthocyanin-rich black plum peel extract. Food Hydrocoll 94:80-92

45. Sadek EM, El-Nashar DE, Ward AA, Ahmed SM (2018) Study on the properties of multi-walled carbon nanotubes reinforced poly (vinyl alcohol) composites. J Polym Res 25:249

46. Sabarish R, Unnikrishnan G (2018) Polyvinyl alcohol/carboxymethyl cellulose/ZSM-5 zeolite biocomposite membranes for dye adsorption applications. Carbohydr Polym 199:129-140

47. Wang T, Li Y, Geng S et al (2015) Preparation of flexible reduced graphene oxide/poly(vinyl alcohol) film with superior microwave absorption properties. RSC Adv 5:88958-88964

48. Das K, Ray D, Bandyopadhyay NR et al (2010) Preparation and characterization of cross-linked starch/poly(vinyl alcohol) green films with low moisture absorption. Ind Eng Chem Res 49:2176-2185

49. Lotfy S, Fawzy YHA (2014) Characterization and enhancement of the electrical performance of radiation modified poly (vinyl) alcohol/gelatin copolymer films doped with carotene. J Radiat Res Appl Sci 7:338-345

50. Gaikwad KK, Lee JY, Lee YS (2016) Development of polyvinyl alcohol and apple pomace bio-composite film with antioxidant properties for active food packaging application. J Food Sci Technol 53:1608-1619

51. Kaczmarek H, Podgórski A (2007) The effect of UV-irradiation on poly(vinyl alcohol) composites with montmorillonite. J Photochem Photobiol A Chem 191:209-215

52. Fabra MJ, Talens $P$, Chiralt A (2009) Microstructure and optical properties of sodium caseinate films containing oleic acid-beeswax mixtures. Food Hydrocoll 23:676-683

53. Liu J, Wang H, Guo M et al (2019) Extract from Lycium ruthenicum Murr. incorporating $\mathrm{K}$-carrageenan colorimetric film with a wide $\mathrm{pH}-$ sensing range for food freshness monitoring. Food Hydrocoll 94:1-10

54. Qin Y, Liu Y, Yuan L et al (2019) Preparation and characterization of antioxidant, antimicrobial and $\mathrm{pH}$-sensitive films based on chitosan, silver nanoparticles and purple corn extract. Food Hydrocoll 96:102-111

55. Nur Hanani ZA, Aelma Husna AB, Nurul Syahida $S$ et al (2018) Effect of different fruit peels on the functional properties of gelatin/polyethylene bilayer films for active packaging. Food Packag Shelf Life 18:201-211

56. Ferreira AS, Nunes C, Castro A et al (2014) Influence of grape pomace extract incorporation on chitosan films properties. Carbohydr Polym 113:490-499

57. Kaya M, Ravikumar P, Ilk S et al (2018) Production and characterization of chitosan based edible films from Berberis crataegina's fruit extract and seed oil. Innov Food Sci Emerg Technol 45:287-297

58. Madera-Santana TJ, Freile-Pelegrín Y, Azamar-Barrios JA (2014) Physicochemical and morphological properties of plasticized poly(vinyl alcohol)-agar biodegradable films. Int J Biol Macromol 69:176-184

59. Nogueira D, Martins VG (2019) Use of different proteins to produce biodegradable films and blends. J Polym Environ 27:2027-2039

60. Mathew S, Jayakumar A, Kumar VP et al (2019) One-step synthesis of eco-friendly boiled rice starch blended polyvinyl alcohol bionanocomposite films decorated with in situ generated silver nanoparticles for food packaging purpose. Int J Biol Macromol 139:475-485

Publisher's Note Springer Nature remains neutral with regard to jurisdictional claims in published maps and institutional affiliations. 